\title{
Three Hurdles to Technology Integration: A Case Study of Technology Integration in Bungamati
}

\author{
Jeffrey Chih-Yih Lee \& Paul Sparks
}

\begin{abstract}
Integrating technology in education is an extraordinary challenge in rural villages of developing countries like Nepal. Since greater understandings of the circumstances surrounding teachers and schools could illuminate issues and opportunities for positive change, a case study of the telecenter in Bungamati, Nepal was conducted. Data, in the form of interviews, observations and related documents, were gathered and analyzed to highlight and understand the local hurdles for integrating technology in teaching. Findings were threefold: teachers lack technology integration skills; informal learning was the preferred way to learn technology; and males had greater access to technology. In this study, the researcher has drawn the following conclusions: a) teachers need technology access and training, $b$ ) administrators need a framework for integration, c) informal learning should be considered and promoted and d) there is a clear need for gender equity. Furthermore, suggestions for future studies include a need for informal learning, the use of the TPACK (Technological, Pedagogical, and Content Knowledge)framework for integration technology and more research in the area of teacher training with technology in other developing countries.
\end{abstract}

Key Words: Teacher Training; Informal Learning; Technology; ICT; Youth

\section{Introduction}

Developing countries such as Nepal struggle to keep up with the $21^{\text {st }}$ Century technology. While advances have made it possible for some Nepali to access technology such as mobile phones, computers, and digital cameras, barriers continue to impede progress. In populated and more developed cities such as Kathmandu, technology has begun to penetrate into the daily lives of teachers and students. However, in rural areas various hurdles act to hinder the actual use of technology in education, yet technology use in education continues to grow in the interest of teachers and students. Nevertheless, there are reports of progress even in rural areas that the use of technology is gaining a foothold and evolving rapidly (Ivins, 2008).

To investigate how teachers and students use technology in a rural setting, a case study of the Tri-Ratna CoOperative Secondary School in Bungamati, Nepal was conducted. This site was strategically chosen because the Bungamati telecenter, a community owned and operated technology center and major source of technology for the 
village, is located at the school and acts as both a telecenter and the school's computer lab. With its relative close proximity to Kathmandu (15km), local villagers seem to be informed of the latest innovations with technology. Most families own mobile devices and some even have a computer at home.

\section{Research question}

This case study took an ethnographic approach to understand how technology is used in education by asking the question, "What are the current conditions of technology use at the Tri-Ratna Co-Operative Secondary School in Bungamati?" The researcher collected data through observations, interviews and examination of documents for a period of 14 days during the summer of 2013. Even though the researcher has been working with the Bungamati telecenter since 2004, observations and interviews took place over 14 days, which warrants this study to be appropriately called a case study with an ethnographic approach.

The purpose of this study was to inform interested parties on the current state of technology in one rural school in Nepal. Hopefully, a greater understanding of current conditions, relationships and circumstances will inform future decisions on technology, education and teacher training.

\section{Review of literature}

\section{Nepal and schools in Nepal}

As a landlocked country located between China and India, two of Asia's superpower nations, Nepal has many geographic and political challenges. While geographically isolated, modern technology has begun to help Nepal engage with countries around the world. This flattened engagement (Friedman, 2006) brings both benefits and challenges.

In the 1990s, Nepal went through 10 years of warfare in which an uprising of the Maoist party forced the king to ultimately step down. When the fighting stopped in 2005, the country suffered heavily with over 10,000 deaths, negative rates of growth and wide economic gaps between urban elites and the rural majority (Carney, Bista, \& Agergaard, 2007).

Looking back at the history of schooling in Nepal, one would discover an increase in public schools from 10,600 schools (1971) to 27,268 (2003). Yet the national enrollment rate was $42.9 \%$ in lower secondary schools and only $26.3 \%$ at the secondary level in 2002. Additionally, the Ministry of Education and Sports reported that boys had greater access to schools than girls(Nepal, 2005).

Public schools also lack formal accountability for teachers, curriculum and budget. In a series of school visits, a Community Development Network's researcher reported that generally, private schools and community schools had higher teacher accountability. A board member of a community school stated in a 2004 interview, "Of course the teacher that the community school pays for is better. She knows that she can get fired if she does not do her job. The government teacher is not as good because the paycheck will always be there at the end of the month" (Lee, 2004).

$106 \quad$ Journal of NELTA, Vol 18 No. 1-2, December 2013 


\section{Teacher training and technology in Nepal}

A review of literature was conducted using all databases within EBSCO's main database. Key words used for this Boolean search were: Nepal, developing countries, education, teacher training, technology and ICT. A variety of combinations were used due to the unique and narrow nature of the topic of this study. When one zooms in, the search yields zero results for "Nepal + Teacher Training + ICT" and "Nepal + Teacher Training + Technology". However, when one zooms out slightly, "Developing Countries + Teacher Training + Technology" yielded 92 results. This signifies an alarming need for such a study to be conducted.

The general lack of articles related to teacher training combined with technology in Nepal is interesting and warrants deeper discussion. The literature search showed the following results:

- Nepal + Education + Technology yielded 41 hits. Upon reviewing these articles, it was evident that most were not related to the integration of technology in education. Instead, most focused on computer science education in Nepal.

- Nepal + Education + ICT yielded 1 hit. The article, Tackling The Problems of Quality and Disparity in Nepal's School Education: The OLPC Model (Bhatta, 2008) looks at the impact of the One Laptop Per Child program in Nepal. The focus of this article is still not directly related to this study.

- $\quad$ Both Nepal + Teacher Training + Technology and Nepal + Teacher Training + ICT are the closest search parameters related to this study, but the search yielded zero peer reviewed findings.

\section{Teacher training with technology in developing countries}

There appears to be some work done in the area of teacher training with technology in developing countries. Despite the lack of Nepali context, 92 articles were revealed in the context of developing countries and the results are significant.

The Open Distance Learning (ODL) movement has become extremely popular in Cambodia, another developing country in South Asia. There is drastic development in using ODL to complement face-to-face education (Grunfeld \& Ng, 2013). With advances in technology, new platforms for learning are leveraged for knowledge sharing and creation.

Similarly, in Jordan, technology has gained popularity with government officials and teachers. In fact, the Ministry of Education recently adopted several technology training courses aimed at preparing teachers to integrate technology effectively across the curriculum (Abuhmaid, 2011). Abuhmaid's study is a landmark study citing the importance of providing teachers proper training in integrating technology. 
In South Africa, Pool, Reitsma and Mentz reveal that proper technology training for teachers focused on teachers' use of technology as subject matter experts (Pool, Reitsma, \& Mentz, 2013). Once the connection is made to subject matter, teachers can then develop appropriate pedagogical approaches to integrating technology.

In Algeria, Guemide and Benachaiba (2012) expanded on the importance of proper teacher training with technology by making the claim that for the purpose of reaching rural communities, eLearning may emerge as a viable solution. This may take shape in both content delivery and co-construction of content by participants (Guemide \& Benachaiba, 2012).

In recent times, more literature is beginning to emerge in the area of developing countries conducting teacher training with technology. This comprehensive review of literature only revealed four related articles, all of which are out of the context of Nepal, which underscores the need for research in the area of teacher training with technology in Nepal.

\section{Methodology}

Due to the multifaceted nature of the problem, a qualitative case study approach was selected. Qualitative research can better take into account the rules that govern human life and social interaction (Seidman, 2006, p. $26)$. Since these rules are always changing, unlike laws of physics, qualitative research allows for a deeper understanding of the phenomenon. Seidman calls this type of study the "work of describing culture" (Seidman, 2006, p. 26).

Patton describes ethnography, a type of qualitative research method, as a "social scientific description of a people and a cultural basis of their peoplehood" (Patton, 2002, p. 81). Since much of the data that governs technology integration is social and cultural in nature, ethnography was chosen as the most appropriate approach for this study.

\section{Data collection}

In June of 2013, the researcher embedded himself in the Bungamati community in an effort to embrace and understand all aspects of using technology for education. The researcher spent the first few days acclimatising to the community to lower any anxiety the youths and other community members may have had about this study.

A total of 27 people were interviewed, resulting in 156 pages of transcripts. Interviews began in groups based on gender and age. Stratifications of age and gender were necessary to pinpoint various points of views of technology for comparative purposes. From the group interviews, individuals were selected for follow-up individual interviews. The interview location was strategically chosen to be neutral and public. For Institutional Review Board (IRB) clearance purposes, youth were categorized as unmarried young adults in age groups $18-22$ or $23-26$.

Direct observations of the telecenter and teachers totaled 20 hours.

$108 \quad$ Journal of NELTA, Vol 18 No. 1-2, December 2013 
Observations took place during open hours of the telecenter and school. Several key documents including telecenter logs, meeting notes and telecenter sustainability plans were also gathered and analyzed.

\section{Ethical considerations}

The researcher used a safe and appropriate yet comprehensive approach to collecting data. The researcher's home institution, Azusa Pacific University, approved the study through an IRB process. Participants signed informed consent letters acknowledging that their personal information would be kept confidential. No one under 18 years of age was interviewed or observed.

Additionally, local community leaders were supportive of the study. Before any data was gathered, the researcher met with the telecenter board and the school principal to plan an inclusive information meeting for the community. At this meeting, community members were invited to learn about the study and to seek answers to any questions or concerns they might have had.

The researcher also utilized the expertise of a local cultural informant with expertise in technology and education. This individual was also highly respected by the Bungamati community.

\section{Strengths and limitations}

One strength of this study is the researcher's level of experience in the area of technology and education in
Nepal. The researcher had nine years of experience working with technology in various Nepali telecenters and communities from villages around Kathmandu to Chitwan to Pokhra. The researcher has worked with the Bungamati community leadership team several times since 2004, when the telecenter was established. Additionally, the researcher was an elementary school teacher for ten years and currently leads teacher preparation graduate courses at Azusa Pacific University.

Another strength is the preparation of the researcher to be non-biased and neutral in his research. He has gone through extensive exercises in calibrating his perspective and used a cultural informant to help clarify questionable or inconclusive data.

One major limitation of this study was time. The researcher only had two weeks to gather the data in Bungamati. Knowing that time was a constraint, the researcher spent eight months prior to arrival in the planning process to ensure that all parties were properly informed and potential concerns were addressed. Follow-up questions and surveys were conducted electronically after the two weeks.

Another limitation is the timing of interviews. Being that the summer months also a harvest season, many of the villagers were tasked with farming duties. As a result, many had a difficult time attending the scheduled interviews, resulting in significant rescheduling. 


\section{Findings}

When taking an ethnographic look at culture, it is important to consider the fact that reliability of data needs to be rigorous and accurate. It is also important to highlight that findings in this study are specific to Bungamati and may not be generalizable to all villages in Nepal. However, attempts have been made to triangulate the data for both internal and external reliability.

\section{Teachers' lack of technology integration skills}

At the Bungamati telecenter, teachers from the Tri-Ratna Co-Operative Secondary School take their classes to the computer lab throughout the day even though most have not received proper training using technology. Only one teacher out of ten ever received advanced computer training (Photoshop and Page Maker). The rest either received no training or what is known as basic computer training (Microsoft Word, Excel, PowerPoint and Internet).

From classroom observations, it can be generalized that students were in the process of learning basic computer skills. These skills parallel the technical knowledge of the teachers. There was no evidence of teachers integrating technology into the curriculum while they were teaching. For example, it was observed that students learned how to use the Internet during the computer lab session. Students freely surfed the web, which signifies that teachers have not fully planned the use of the Internet to enhance the teaching of content such as mathematics, science and history.
The principal and teachers perceived of the role of technology very differently. The principal wanted teachers to be trained in "Applications, Networking, Computer Maintenance, Web Design and Photoshop". Teachers, on the other hand, wanted training in "using technology in teaching and learning in school." In fact, teachers seemed enthusiastic at opportunities to learn how to integrate technology in teaching.

Knowing that many of his students go home and Google search various topics he teaches in class, one teacher stated, "I don't think [having technology at home] lowers the value of the teacher. They go home and learn something from the Internet and then they come to school and ask questions to the teacher. I think this increases the capacity of teachers as well." Another teacher stated, "Because we lack proper curriculum and teacher training, I often go to the telecenter after school to search on Google and copy/ paste for my students".

Recognizing that young people are better skilled with technology, two teachers shared that they go outside the school system for training and support. They invested their own time and money to get training because they feel the students are coming to school with more questions than ever before and they must adapt to the demands of the students.

\section{Informal learning is the preferred way to learn technology}

Nepali schools are very formal in nature. Teachers typically stand at the front or center; students sit in rows and can be 
seen taking notes during lectures. When asked what is the preferred way to learn technology, unanimously, students voiced their preference for informal learning.

Many young people share this outlook: "Internet helps me develop many things. If we have questions, then we use Google." When asked about the balance of formal and informal learning, a 23-year-old male respondent said, "Informal learning is good. But for basic things such as school, formal is good. But for advanced things, informal is good." Further investigation uncovered that young people refer to what the teachers teach as "basic". When they are interested and want to learn more, the things they learn online are then referred to as "advanced".

Such findings parallel American youth culture with technology, based on Ito's report, Living with New Media(Ito, 2008). They enjoy what Ito calls "hanging out", "messing around" and "geeking out". They like playing on Facebook, Google and YouTube and informally learn a wide variety of things that are interest driven. In fact, Primmer's study of undergraduate students in Nepal documents that students used Facebook on a daily basis to share, learn and communicate (Primmer, 2012).

\section{Boys have more access to technology}

This study confirms the gender divide between girls and boys as previously cited in a telecenter study in Sankhu, Nepal (Lee, 2010). Like Sankhu, Bungamati female youth are tasked with more chores around the house. They typically are responsible for cooking, cleaning and working in the fields. Although girls are becoming more educated through formal schooling, their chores stop them from full access to technology.

One elder man explained, "In our Nepali society, we are quite restricted to send the female around. If a female is going somewhere alone, then everyone will raise the question, 'how can she go?' This type of question creates problems." As a result, telecenters are rarely used by females, as evidenced by both observations and telecenter sign-in logs.

An elder woman sarcastically shared, "Even if I wish to learn computers, and I had someone to teach me, my son would not allow it (laughter). He would say “you couldn't learn.'" To further validate such an outlook on the abilities of women, a 24-year-old male stated, "We think boys are more important than girls. There is gender inequality in our society. Parents prefer boys than girls. They prefer son to daughter. That is why there is an easier time for boys to use the Internet than girls."

In summary, the findings fall into three distinct areas. First, teachers lack technical skills and curriculum integration skills. Technology is more abundant in recent times, thus allowing students to gain more access, learn additional content and collaborate more with others. As a result, teachers have fallen behind and have not adapted to the new ways students learn through technology. Second, informal learning 
is the preferred way youth learn technology. This parallels much of the findings in other parts of the world. What is significant in this study is that young people actually perceive schooling as "basic" and what they learn online as "advanced". Third, boys continue to have more access to technology, compared to girls. In 2013, this cultural obstacle seems to be more openly addressed, but the divide between boys and girls still exists.

\section{Conclusion and suggestions for future studies}

The data from this study and previous literature suggest the following conclusions:

1) Teachers need technology access and training. Teachers need access, basic skills and technology integration training. Access to technology, especially in rural areas, remains a challenge. Although the government of Nepal responded to local demands in 2004 with the creation of telecenters, many of these telecenters struggle for sustainability. Recent improvements in mobile technology have created a phenomenon where local villagers have leapfrogged over telecenter access to low cost mobile access. Unfortunately, schools have fallen behind in this process.

Teacher training on basic computer skills is a necessary first step. However, beyond training teachers in basic skills, teachers must also be trained on how to properly integrate technology into their lessons.

2) School administrators need a framework for integration. Expanding on the need for technology integration training, Nepal vitally needs to adopt a national framework for technology integration. After careful consideration of various technology integration models, this study suggests adopting the Technological, Pedagogical, Content Knowledge (TPACK) framework, a widely adopted framework for technology integration.

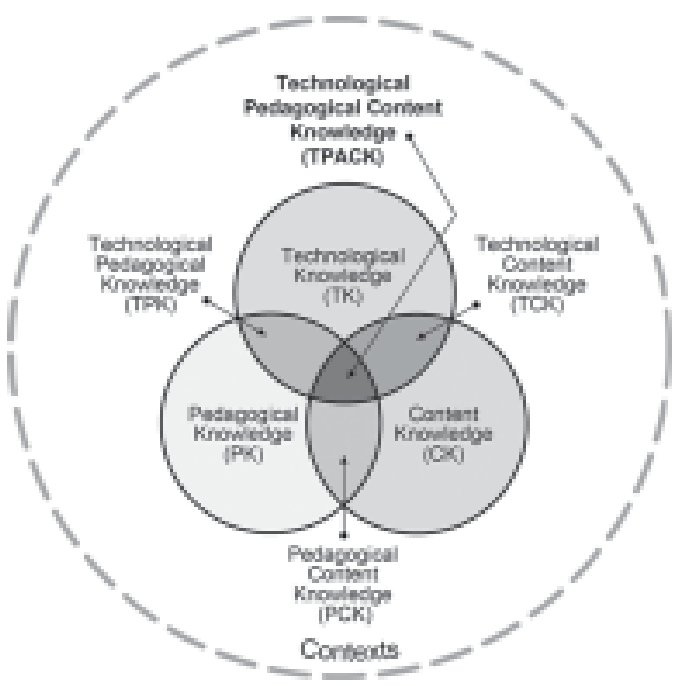

Figure 1: TPACK Framework, adopted from www.tpack.org

Using TPACK, teachers can properly utilize, analyze and evaluate various ways technology integration impacts pedagogy and content(Koehler, 2011). By widely adopting the TPACK framework, there can be a national common understanding and approach 
to integrating technology in teaching. As seen in Figure 1, the overlap between the three circles, also labeled TPACK, represents where good technology integration takes place.

1) Informal learning should be considered and promoted. Like young Americans, the youth in Nepal also prefer informal learning. Informal learning in both small and large communities of practice has become a preferred way to learn in the $21^{\text {st }}$ Century, as evidenced by Ito's report(Ito, 2008). Although there always will be a need for formal learning, informal learning should be considered when designing learning opportunities in classrooms. Furthermore, teachers in the $21^{\text {st }}$ century should consciously weave learning opportunities in and out of the formal and informal.

2) There is a clear need for gender equity. Many previous studies have cited that gender inequality exists in Nepal. Despite recent governmental support for equity, realities of daily Nepali life negatively impacts young girls from accessing education and technology; gender equity challenges prohibit girls from full engagement with opportunities, especially in the area of technology and education. This study suggests a systematic program for engaging young girls in using technology. Examples of activities include allowing girls to check out mobile devices such as smartphones to be used around their household chore schedules, more opportunities for girls to use technology in schools and telecenters, and technology clubs for girls.

\section{Suggestions for future studies}

Below are three suggestions for future studies based on the findings of this study.

1) A study on the culture of informal learning with technology in Nepal, specifically focusing on youth in rural areas.

2) A longitudinal study on technology integration by teachers using the TPACK model, specifically looking at the impact of effective technology integration in the context of developing countries.

3) Further studies focusing on teacher training with technology in other developing countries around the world.

The findings from this study suggest that the ways Nepali youth use technology as tools for learning are changing as quickly as the technologies themselves. Communities in developing countries are in a pivotal position to make impactful changes and should consider the role of technology. When leveraged appropriately, technology can bridge significant divides.

\section{About the authors}

Dr. Jeffrey Lee is an associate professor at Azusa Pacific University where he teaches courses in teacher education and digital teaching and learning. His research interests lie in the intersection of education, technology and developing countries. He has completed three ethnographic studies focusing on youth culture with technology in Nepal. 
Dr. Paul Sparks is an associate professor at Pepperdine University where he teaches doctoral and masters courses in learning technologies. He was also an educational technologist and information systems specialist for Rockwell International. Dr. Sparks has also been a part of several technology and education initiatives in Nepal.

\section{References}

Abuhmaid, Atef. (2011). ICT Training Courses for Teacher Professional Development in Jordan. Turkish Online Journal of Educational Technology - TOJET, 10(4), 195-210.

Bhatta, Saurav Dev. (2008). Tackling The Problems of Quality and Disparity in Nepal's School Education: The OLPC Model. Studies in Nepali History \& Society, 13(1), 17-47.

Carney, Stephen, Bista, Min, \& Agergaard, Jytte. (2007). 'Empowering' the 'local' through education? Exploring community-managed schooling in Nepal. Oxford Review of Education, 33(5), 611-628. doi: 10.1080/ 03054980701476253

Friedman, Thomas. (2006). The World Is Flat: A Brief History Of The Twenty-First Century. New York: Farrar, Straus and Giroux.

Grunfeld, Helena, \& Ng, Maria Lee Hoon. (2013). A Multimedia Approach to ODL for Agricultural Training in Cambodia. International Review of Research in Open and Distance Learning, 14(1), 222-238.

Guemide, Boutkhil, \& Benachaiba, Chellali. (2012). Exploiting ICT and E-Learning in Teacher's Professional Development in Algeria: The Case of English Secondary School Teachers. Turkish Online Journal of Distance Education, 13(3), 33-49.

Ito, Mimi. (2008). Living and Learning with New Media. In T. M. Press (Ed.), Building the Field of Digital Media and Learning. The Massachusetts Institute of Technology.

Ivins, Tiffany Zenith. (2008). Microfranchising Microlearning Centers: A Sustainable Model for Expanding the Right to Education in Developing Countries? Journal of Asynchronous Learning Networks, 12(1), 27-35.

Koehler, TPACK and Matthew J. (2011). TPACK. Retrieved 9/15/2013, 2013, from http://tpack.org

Lee, Jeffrey Chih-Yih. (2004). CDN Field Notes (pp. 26). Kathmandu: Community Development Network.

Lee, Jeffrey Chih-Yih. (2010). Tensions in a Nepali Telecenter: An Ethnographic Look at Progress Using Activity Theory. ProQuest LLC. Available from EBSCOhost eric database.

Nepal, Ministry of Education and Sports of. (2005). Nepal in Educational Figures. Kathmandu, Nepal.

Patton, Michael. (2002). Qualitative Research $\mathcal{E}$ Evaluation Methods. Thousand Oaks, CA: Sage Publications Inc.

Pool, Jessica, Reitsma, Gerda, \& Mentz, Elsa. (2013). An Evaluation of Technology Teacher Training in South Africa: Shortcomings and Recommendations. International Journal of Technology and Design Education, 23(2), 455-472.

Primmer, Christoph and Linxen, Sebastian. (2012). Facebook as a Learning Tool? A Case Study on the Appropriation of Social Network Sites From Mobile Phones in Developing Countries. The British Journal of Educational Technology, 43(n5), 726-738.

Seidman, Irving. (2006). Interviewing as qualitative research : a guide for researchers in education and the social sciences (3rd ed.). New York: Teachers College Press. 